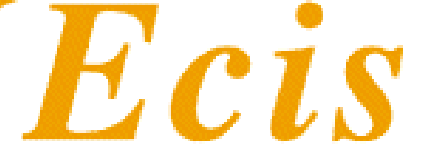

Eindhoven Centre for Innovation Studies

\title{
Developing Alliance Capabilities in a New Era
}

G.M. Duysters \& K.H. Heimeriks

Eindhoven Centre for Innovation Studies, The Netherlands

Working Paper 03.19

Department of Technology Management

Technische Universiteit Eindhoven, The Netherlands

July 2003 
Developing Alliance Capabilities in a New Era

\section{Geert M. Duysters}

Department of Organization Science

Eindhoven University of Technology,

The Netherlands

$\risingdotseq$ PO. Box 513

NL - 5600 Eindhoven, The

Netherlands

g.m.duysters@tm.tue.nl

笛 ++ 31402473972

Fax ++31402468054

\section{Koen H. Heimeriks}

Department of Organization Science

Eindhoven University of Technology, The

Netherlands

$\fallingdotseq$ PO. Box 513

NL - 5600 Eindhoven, The

Netherlands

k.h.heimeriks@tm.tue.nl

椆 ++ 31402474435

Fax ++31402468054 


\section{ABSTRACT}

Recent empirical research suggests that, despite unprecedented attention on alliance management in the academic and management literature, failure rates of alliances remain at a very high level. On the basis of a global survey among alliance managers, this paper aims to reveal recent trends in alliance capability building and tries to uncover novel ways in which firms try to enhance their alliance performance.

\section{INTRODUCTION}

Despite the unprecedented increase in the number of newly established strategic alliances (Bekkers, Duysters and Verspagen, 2002), alliance performance has remained weak over the last decades. Most scholars report failure rates that vary between 40 and 70\% (for an overview see Park and Ungson, 2001). Given the fact that revenues derived from alliances have also increased steadily over the past decade (Margulis and Pekar, 2001), it becomes a key managerial challenge for firm's to understand how to enhance overall alliance performance. In this paper we define strategic alliances as cooperative agreements in which two or more separate organizations share reciprocal inputs, while maintaining their own corporate identities (Vanhaverbeke, Duysters and Noorderhaven, 2002).

Recent research has shown that firms develop alliance capabilities in many different ways (e.g. Hill and Hellriegel, 1994). Some firms rely on gathering and dispersing generalized alliance knowledge, while other firms abide by case-specific material to increase their alliance performance (Alliance Analyst, 1995). However divergent the ways to develop alliance capabilities may be, so far scholars' attempts to discern how firms build these capabilities have remained scarce (Simonin, 1997). One of the few empirical papers on the relevance of building capabilities using dedicated mechanisms was written by Kale, Dyer and Singh (2002). They found that an alliance function or department added significantly value to a firm's alliance performance. Little, however, is known about the way in which firms can develop such a capability. This paper seeks to unravel the recent developments in the field of alliances to gain a better 
understanding of critical mechanisms that firms use to build alliance capabilities in order to enhance their alliance performance.

The aim of this paper is threefold. First, we analyze recent developments in the field of academic research and practice. On the basis of a recent empirical investigation, we discuss the alliance performance of global alliance managers and the market value they generate through alliances. Second, on the basis of recent research, we aim to enhance current insights into critical issues in alliance capability development. Third, we show the critical mechanisms that firms use to manage their alliances in order to enhance their alliance capabilities. To realize these goals, this paper first retrospectively reviews some important developments in alliance research. Then, we present results of a recent worldwide study among 151 firms, thereby underlining the importance of alliances as a revenue generator and addressing the mechanisms firms can use to manage their alliances more successfully.

\section{THEORETICAL BACKGROUND}

Over the past decades, numerous researches have been triggered by the growing importance of alliances. Over time the main research emphasis of scholars concerned with the antecedents of alliance performance has changed dramatically. Traditionally, scholars focused their attention to factors influencing alliance performance in the relationship. Traditional academic literature, such as transaction cost theory and industrial organization theory, considered alliances as a second-best option to goingalone or full hierarchical integration of companies (Contractor and Lorange, 1988). Moreover, alliances were viewed as distinct business transactions, which led researchers to focus on critical aspects in the alliance itself (e.g. Steiner, 1968).

This early research into antecedents of alliance performance was centered around critical factors in the dyadic relationship. Scholars devoted particular attention to the critical factors that should be taken into account when managing the individual alliance. For instance, trust and complementarity were supposed to be critical in enhancing alliance performance (Johnson et al., 1996). Overall, referring to e.g. collaboration-specific rents (Madhok and Tallman, 1998) and relational rents (Lane 
and Lubatkin, 1998), these studies provided a vast amount of academic literature on alliance-specific factors that were supposed to optimize alliance performance.

Although these studies have generated interesting contributions, they are unable to explain persistent differences in firms' alliance performance. Ireland et al. (2002, pp. 114) have proposed the need for firms to simultaneously concentrate on both content and process to enhance alliance performance. In their view, it is insufficient to understand the critical issues at the dyadic level without addressing the processes and mechanisms that underline successful alliance management. In an attempt to fill this gap, researchers have started to analyze managerial processes, tools and routines in order to explain for the reported fixed-firm effects in alliance performance. These studies concentrate on firm-level factors rather than dyadic factors as antecedents of alliance performance. Firms that consistently generate above-average rents in alliances are supposed to possess specific alliance capabilities (Kale and Singh, 1999). Building on theories such as evolutionary economics, the resource-based view and the dynamic capability perspective, scholars proposed that these specific capabilities can be viewed as a rare, valuable and difficult to imitate resource at the company level (Gulati, 1998) and have an important impact on rent generation in alliances (Khanna et al., 1998). Overall, these studies underscore the need to build alliance capabilities in order to enhance the performance of a firm's alliance portfolio. Consequently, a firm's alliance portfolio rather than the individual alliance becomes the unit of analysis.

In these contributions, alliance experience has become a central and recurrent theme. Although various scholars have put forward experience as a critical factor for alliance performance, the links between experience, alliance capabilities and alliance performance have not been clearly established (Rugman and Verbeke, 2002). Consequently, in spite of the findings that accumulated experience can have a positive influence on learning (Pisano et al., 2001), to date little attention has been devoted to ways in which firms can build alliance capabilities in order to leverage their alliance performance. A few recent exceptions are studies by Nault and Tyagi (2001) and Kale et al. (2002). They specify a number of mechanisms that firms should employ in order to realize the potential learning effects that eventually enhances alliance performance. 
It is suggested that an alliance capability is a result of the use of mechanisms that enable firms to optimize their resource deployment in alliances.

This paper combines traditional and more recent approaches to alliance research. Not only do we analyze the dyadic factors important in alliance management, but we also investigate specific mechanisms that firms use to develop an alliance capability. After providing an outline of this study's research design, this paper describes the following issues. First, we investigate the importance of strategic alliances for firms. More specifically, we analyze the overall percentage of market value generated by alliances according to the firms that feature in our study. Second, we build on traditional alliance research by analyzing critical dyadic factors. The reasons for alliance failure are rated in order to understand the main hazards in the alliance. Third, we specify alliance goals and outcomes as a means to analyze for what reasons alliances are formed and to what extent the original goals are achieved. Fourth, building on a recent notion that firm-level mechanisms can significantly influence alliance performance, we identify the top 10 alliance mechanisms firms use to develop their alliance capability.

\section{RESEARCH DESIGN}

In order to study these particular issues, a survey was conducted among 1000 VP's of alliance and alliance managers. A database of the Association of Strategic Alliance Professionals (ASAP), was used to address the mailing to VP's and top managers in charge of corporate alliance management. This allowed us to ensure that our respondents where adequately aware of critical and detailed issues about their firm's alliance activities. The survey was sent out to the respondents, where after we send out a reminder in order to maximize the response rate. The survey consisted of closed questions and respondents were asked to rate their answers on a 5-point Lickert scale. Although information gathering via self-reporting can limit the validity of the results, the data was extensively screened to delete invalid cases and other errors. Eventually we came up with a sample of 151 respondents. The final data set consists of respondents from various different industries: 43\% ICT-related business, $7 \%$ financial services, $25 \%$ other services (e.g. consultancies), $11 \%$ manufacturing, $6 \%$ public sector, $5 \%$ pharmaceuticals and biotechnology and 3\% chemicals. 


\section{ANALYSIS \& RESULTS}

In the context of this research, alliance performance is considered as the main dependent variable. In line with earlier studies (Hamel et al., 1989), we defined alliance performance as the percentage of alliances in which the firm's goals were realized over the last 5 years. As described above, the unit of analysis is a firm's alliance portfolio. Our research indicates that the average alliance performance is $52 \%$, which is comparable to earlier studies.

The analysis of the data led to a number of interesting findings. First of all, we investigated the relevance of alliances for the respondents by analyzing the current and expected future market value generated by alliances. The respondents indicated that they expect the importance of alliances for their respective firms(measured as the percentage of the firm's market value coming from alliances) to increase dramatically. Figure 1 shows that firms find alliances to represent an increasing percentage of their market value. The pie chart presented at the left side is the respondents' current market value coming from alliances. The larger part, that is $47 \%$ of the respondents, positions itself in the category in which between 21 to $40 \%$ of a firm's market value is generated via alliances. The graph at the right hand side represents the expected market value coming from alliances in five years. Our respondents indicate that they expect a significant increase with respect to the value generated via alliances, since the largest category has shifted from $21-40 \%$ to $41-60 \%$, consisting of $34 \%$ of the respondents.

Figure 1 Comparing company’s current and future market value coming from alliances 

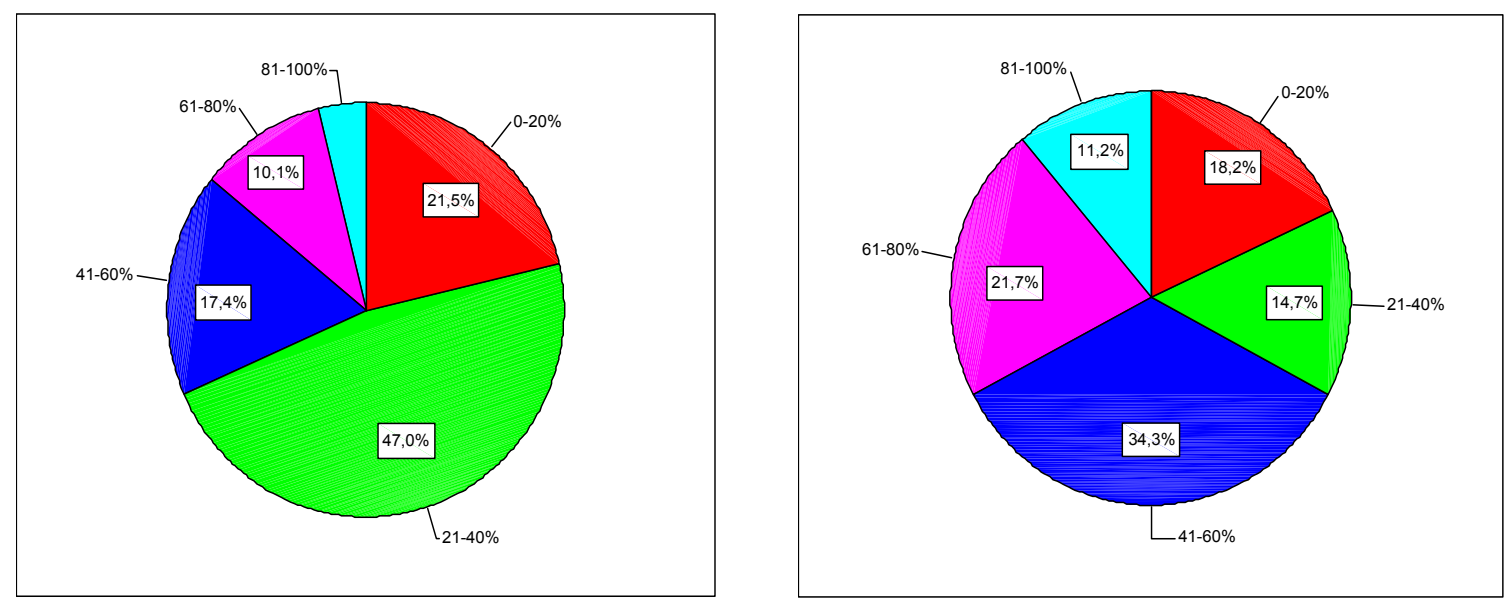

Looking at Figure 1, it becomes apparent that respondents expect a clear increase in market value arising from alliances. Whereas currently an average of $36 \%$ of the respondents market value is generated via alliances, they expect $49,1 \%$ to be generated via alliances in the coming five years. These results support the findings by Harbison et al. (2000), which report that alliances are responsible for an increasing percentage of firm's revenues.

The second aim of this paper is to uncover critical elements in managing the individual alliance. This was done by analyzing the reasons for alliance failure ${ }^{1}$ and by studying the original goals as set during the formation of the alliance. In our study we defined ten major categories of reasons for alliance failure as found in the literature: (1) mismatch of partner's strategy, (2) mismatch of partner's structure, (3) mismatch of partner's culture, (4) lack of trust, (5) partner's inability to deliver expected competences, (6) our own inability to deliver expected competences, (7) operational problems, (8) legal issues, (9) language barriers and (10) government intervention. Respondents rated these items on a 5-point Lickert type scale with the additional option to indicate whether a particular reasons was applicable or not. Figure 2 shows the five most important reasons for alliance failure.

\footnotetext{
${ }^{1}$. For an overview of reasons of alliance failure, we refer to Duysters et al. (1999).
} 
Figure 2 Top 5 reasons for strategic alliance failure

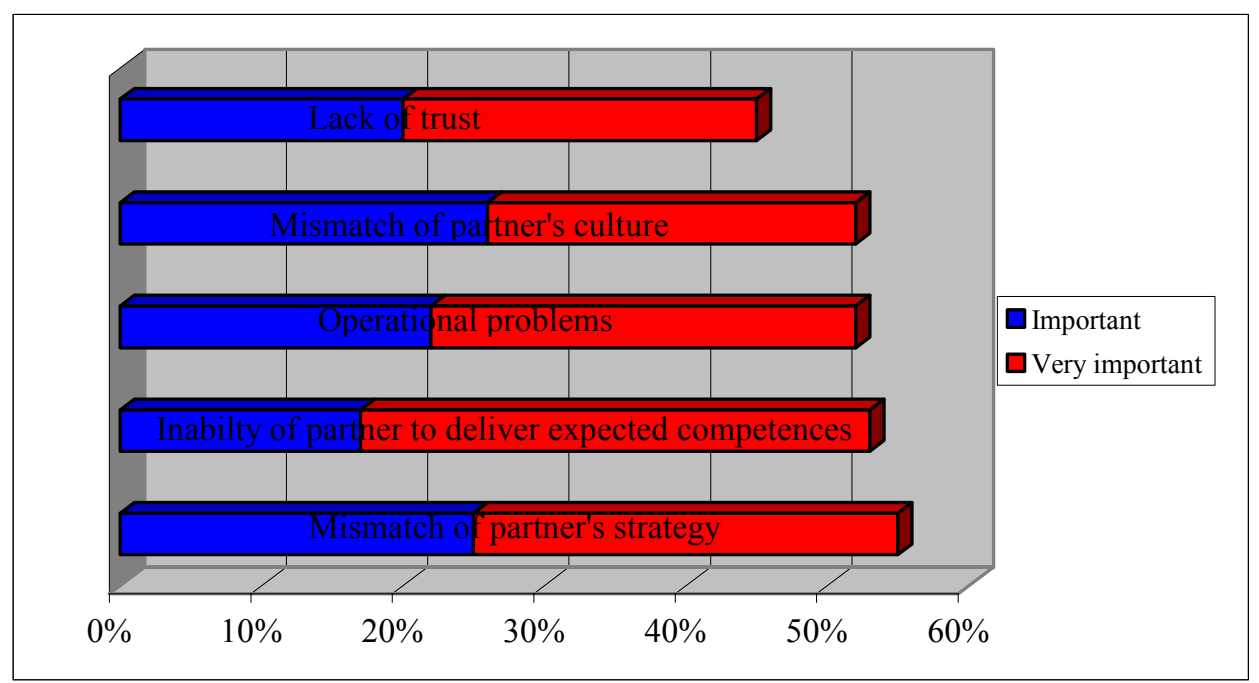

The most important reason for strategic alliance failure is the mismatch of partner's strategy. As indicated by various authors (see e.g. Lorange and Roos, 1993), it is critical for partners to clearly align their strategic intentions with regard to their joint activities. In many cases partners are unable to define clear objectives. Partners should, for example, agree on the scope of the alliance (Doz and Hamel, 1998). The likelihood that the alliance will persist over time is highest if the partners are able to create common benefits (Khanna et al., 1998).

The second most important element to explain alliance failure is the inability of a partner to deliver expected competences. The timing and quality of the resources committed to the alliance can positively influence the success of the alliance (Harbison and Pekar, 1998). Committing resources of an inferior quality to the alliance can become detrimental to the other partner's commitment and survival of the alliance in the end. Moreover, using hidden agendas in order to pursue gains in knowhow is unlikely to provide stability in cooperative arrangements (Hagedoorn, 1990). Thus, the stability of an alliance can be greatly enhanced if all partners make balanced and complementary contributions (Porter and Fuller, 1986).

The third important reason for alliance failure is related to operational problems. Even if strategic issues such as aligning partner strategies and delivering competences are taken care of in a satisfactory manner, failure looms when operational issues are not sufficiently guarded. The mismatch of operational policies, such as control 
management and production procedures, can limit the effectiveness of the alliance. Partners should therefore devote sufficient time and resources to define their joint ambitions at the operational level. Furthermore, they should make clear how these ambitions can be realized. A useful way to avoid operational problems is to inform employees and use their collective know-how to align potential operational pitfalls.

The fourth main reason for alliance failure is a mismatch of the partner's culture. A lack of cultural fit can be an important reason for alliance failure, especially when firms cooperate very intensively. In the case of close cooperation, an effective method to circumvent culture clashes is the incorporation of a new entity or a joint venture. However, this form of strategic allying generally requires considerable financial commitments.

The fifth reason for alliance failure is a lack of trust between the partners. The right mix of trust and formal contracting has been found to improve the cooperative interactions (Poppo and Zenger, 2002). Moreover, as trust is an essential component in social interactions and firms can learn through these interactions, alliance performance can be positively influenced by a high level of trust (Johnson et al., 1996). However, it takes time to realize a high level of trust among partners and therefore firms tend to duplicate their existing ties by teaming up with former allies. Although this can create a high level of mutual trust, it does not guarantee a successful partnership. As this study and many others demonstrate that among others strategy alignment, operational problems are also essential topics to be managed.

The third main research issue is concerned with the original goals and the extent to which these were successfully achieved. Various scholars have come up with many different reasons or motives why firms tend to ally (see e.g. Spekman et al. 1999). However, little research has been done to what extent firms are able to realize the defined goals. In our study five main categories were used to establish the primary motivations of firms to ally and the extent to which these particular goals are realized: (1) risk reduction, (2) economies of scale, (3) market entry, (4) co-opting or blocking competition and (5) access skills and resources. Despite the increase in importance of alliances as market value generator, our study shows that firms have great difficulty in realizing the objectives set. Figure 3 shows the results. 
Figure 3 Alliance goals and outcomes

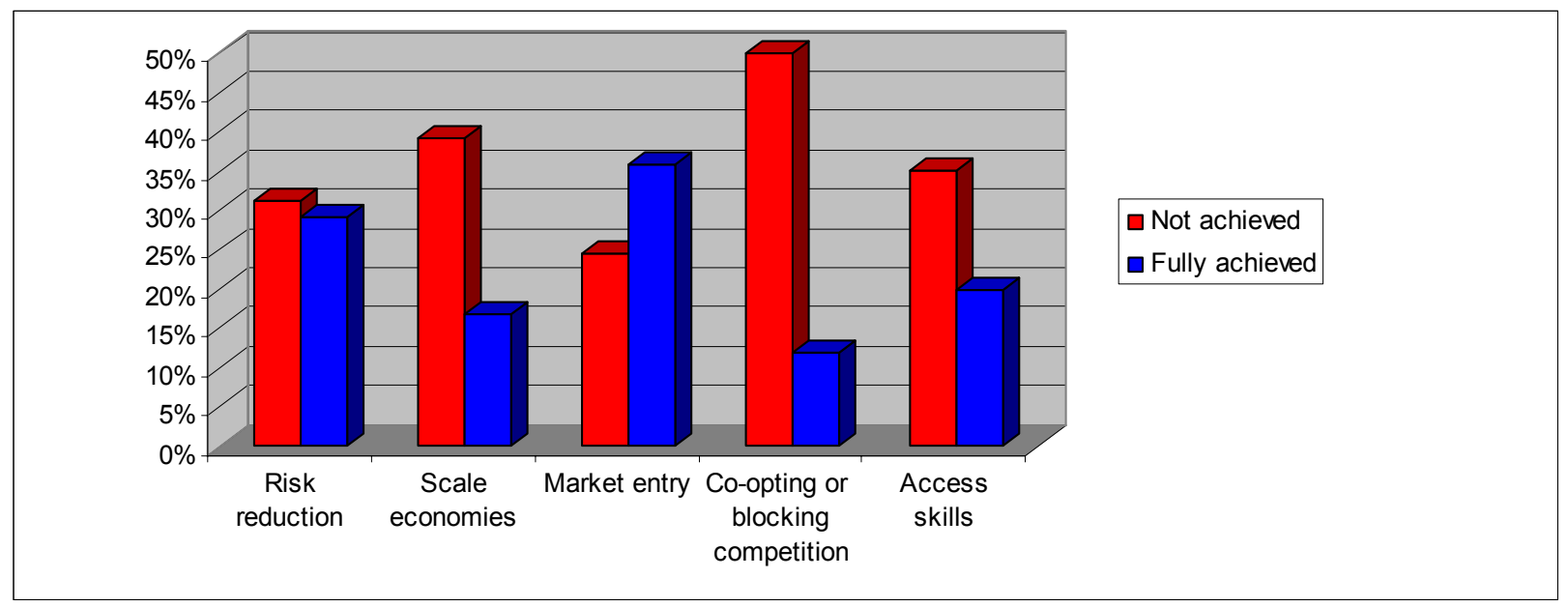

Only alliances aimed at facilitating new market entry (i.e. by entering new product or geographical markets) do fully achieve their goals in $35,8 \%$ of the cases. This is the only goal that showed higher success $(35,8 \%)$ than failure rates $(24,4 \%)$. Especially alliances aimed at co-option or blocking competition experience high failure rates: $50,0 \%$ of respondents say they do not achieve these objectives. This particular goal turns out to be the one that is most difficult to realize.

The fourth aim of this paper is concerned with the extent to which firms use mechanisms to manage their alliances. In order to investigate this particular issue, we performed an extensive literature review and a review of reported practitioner experiences Eventually, we came up with 30 alliance mechanisms that can be used to enhance alliance performance .These 30 mechanisms were divided into four categories. The first category consists of 'functions', which refer to structural mechanisms or management positions that can perform critical issues with regard to a firm's alliances. For instance, a VP of alliances or alliance department can aid in dealing with day-to-day management practices of alliances, but also play a role in acquiring, developing and disseminating specific knowledge and resources (Alliance Analyst, 1996). The second group of mechanisms consists of 'tools', which are practical mechanisms that provide support with regard to for instance a particular stage of alliance life-cycle. In this way, they support 'functions' in a practical manner by i.e. easing the accessibility of specific knowledge via an alliance database, intranet or an alliance training program. 'Control and management processes' form the third 
group of mechanisms available to firms. These mechanisms facilitate in particular the management responsibility for alliances. For instance, the use of alliance metrics or the use of rewards and bonuses to managers can prove efficient in stimulating alliance performance. Fourth, firms can turn to external parties as a means to help increase their performance. Consultants, lawyers, mediators or financial experts may provide for an efficient way to build alliance capabilities (Alliance Analyst, 1995). The following figure summarizes the four categories of alliance mechanisms.

Figure 4 Firm-level mechanisms

\begin{tabular}{|c|c|c|c|}
\hline Functions & Tools & $\begin{array}{l}\text { Control and } \\
\text { management } \\
\text { processes }\end{array}$ & External parties \\
\hline $\begin{array}{l}\text { Vice-president of } \\
\text { alliances (1) }\end{array}$ & $\begin{array}{l}\text { Internal alliance } \\
\text { training (7) }\end{array}$ & $\begin{array}{l}\text { Responsibility level } \\
\text { for alliances }(20)\end{array}$ & Consultants (27) \\
\hline $\begin{array}{l}\text { Alliance } \\
\text { department (2) }\end{array}$ & $\begin{array}{l}\text { External alliance } \\
\text { training (8) }\end{array}$ & $\begin{array}{l}\text { Rewards and } \\
\text { bonuses for } \\
\text { alliance manager } \\
(21)\end{array}$ & Lawyers (28) \\
\hline $\begin{array}{l}\text { Alliance specialist } \\
\text { (3) }\end{array}$ & $\begin{array}{l}\text { Training in } \\
\text { intercultural } \\
\text { management (9) }\end{array}$ & $\begin{array}{l}\text { Rewards and } \\
\text { bonuses for } \\
\text { business managers } \\
\text { (22) }\end{array}$ & Mediators (29) \\
\hline $\begin{array}{l}\text { Alliance manager } \\
\text { (4) }\end{array}$ & $\begin{array}{l}\text { Partner selection } \\
\text { program (10) }\end{array}$ & $\begin{array}{l}\text { Formally structured } \\
\text { knowledge } \\
\text { exchange between } \\
\text { alliance managers } \\
\text { (23) }\end{array}$ & $\begin{array}{l}\text { Financial experts } \\
\text { (30) }\end{array}$ \\
\hline $\begin{array}{l}\text { Gatekeeper or } \\
\text { boundary spanner } \\
\text { (5) }\end{array}$ & $\begin{array}{l}\text { Joint business } \\
\text { planning (11) }\end{array}$ & $\begin{array}{l}\text { Use of own } \\
\text { knowledge about } \\
\text { national differences } \\
\text { in international } \\
\text { alliances (24) }\end{array}$ & \\
\hline $\begin{array}{l}\text { Local alliance } \\
\text { manager }(6)\end{array}$ & $\begin{array}{l}\text { Alliance database } \\
(12) \\
\text { Use of intranet to } \\
\text { disperse alliance } \\
\text { knowledge (13) } \\
\text { Alliance best } \\
\text { practices (14) } \\
\text { Culture program } \\
\text { (15) } \\
\text { Partner program } \\
\text { (16) } \\
\text { Individual }\end{array}$ & $\begin{array}{l}\text { Alliance metrics } \\
(25) \\
\text { Country-specific } \\
\text { alliance policies } \\
(26)\end{array}$ & \\
\hline
\end{tabular}


evaluation (17)

Comparison of

alliance evaluations

(18)

Joint evaluation

(19)

Having specified the various mechanisms that firms can employ to successfully manage their alliances, the next figure presents the top ten of most widely used alliance mechanisms. First, a striking $89 \%$ of the respondents confirms the use of a partner program to manage their alliances. A partner program is defined as a tool that describes different types of alliances and accompanies alliance management processes. Second, $72 \%$ of the respondents makes use of alliance specialist, someone who knows much about alliance management and supports alliance managers in their day-to-day activities. Third, $70 \%$ of the respondents uses an alliance database containing information about the firm's alliance experiences so far. Fourth, $65 \%$ of the respondents evaluates its alliances separately. Fifth, joint business planning, which has been defined as a standardized approach to define a business plan together with partners, is used by $54 \%$ of the respondents. Sixth, a standard partner selection approach is used by $52 \%$ of the respondents. Seventh, an alliance manager is in place in $50 \%$ of the respondent firms, while $48 \%$ uses intranet to disperse alliance-related information. Ninth, $45 \%$ uses an alliance department or alliance function to internally organize and structure alliance management. Finally, $42 \%$ says it uses joint evaluation to assess the alliance performance. Joint evaluation is different from individual alliance evaluation as this can be done in-house rather than in cooperation with the actual partner(s). 
Figure 5 Bart chart of Use of alliance mechanisms in percentages

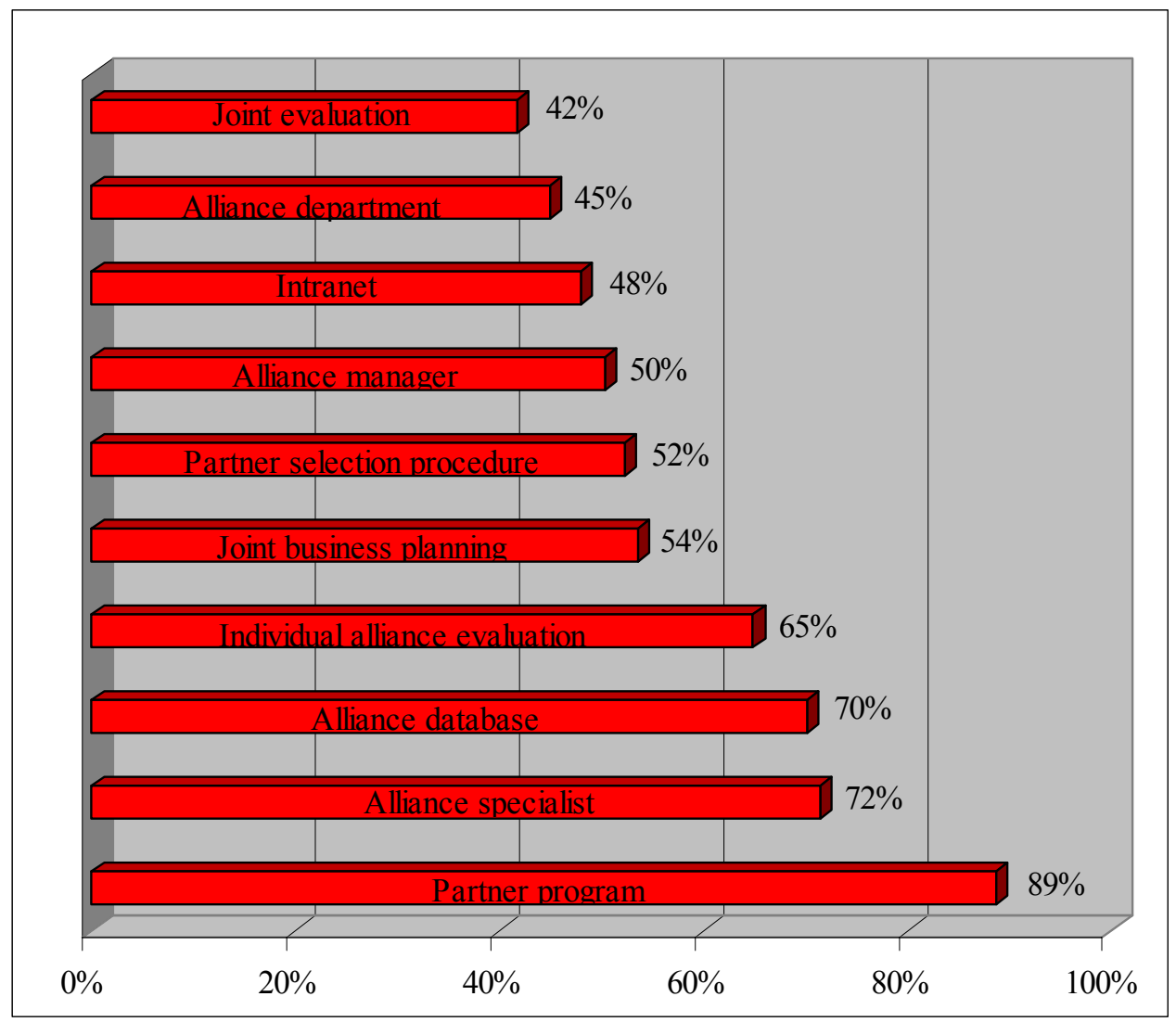

This figure indicates that our respondents make extensive use of the mechanisms listed. Moreover, it also seems that these mechanisms are considered useful ways to enhance a firm's alliance performance. The large number of companies using, for instance, a partner program (89\%) suggests that firms expect this tool to be at least useful and facilitative to its partnering process. Moreover, $70 \%$ of our respondents uses an alliance database as a tool to disperse alliance-related knowledge. This figures provide some insight into what mechanisms firms rely upon in their quest for improved alliance performance.

\section{COONCLUSIONS AND MANAGERIAL IMPLICATIONS}

Having analyzed various critical issues in alliance management using a worldwide survey, a number of important implications can be distilled from the results. First of all, we find that our respondents foresee a vast growth in the importance of strategic alliances for their firms. In line with earlier studies (Harbison and Pekar, 1998; 
Harbison et al., 2000), the percentage of revenues coming from alliances is subject to a relative growth rate of $36 \%$, growing from an average $36 \%$ in 2001 to $49 \%$ in 2006 . The increasing percentage of revenues that firms expect to derive from strategic alliances underscores the need for firms to pay particular attention to alliance capability development. Since strategic alliances have become an important strategic weapon the need to be able to successfully manage them becomes increasingly important. Second, with respect to critical dyadic factors, we find that in line with earlier research strategic, resource, operational and cultural fit as well as trust are highly relevant concepts. Individual partners should seriously commit to ensuring that these topics are well worked out before the alliance becomes operational. Third, we find strong performance differentials among the various alliance goals that are set for alliances. Especially alliances aimed at co-opting and blocking competition are found to be subject to high failure rates. Although it may not be very surprising that competitive battles are likely to raise risks associated with alliances, it is even more striking that alliances aimed at realizing scale economies also perform weakly. Only alliances that are aimed at entering new product or geographical markets are relatively successful. Fourth, although different firms are renowned for using different ways to increase their alliance performance, our results point to a number of mechanisms that are widely applied by our respondent firms. Especially partner programs, alliance specialists and databases are in use by a large majority of the firms. These mechanisms may be an important way to internalize certain experiences and therefore enhance the development of a firm's alliance capability. 


\section{REFERENCES}

Alliance Analyst (1995) Two grandmasters at the extremes, November 1995, NewCap Communications: Philadelphia, PA.

Alliance Analyst (1996) Arguing the collaborative core, April 1996, NewCap Communications: Philadelphia, PA.

Bekkers, R, Duysters, G and B. Verspagen (2002) Intellectual property rights, strategic technology agreements and market structure: The Case of GSM, Research Policy, 31, 1141-1161.

Contractor, F.J. and Lorange, P. (eds.) (1988) Cooperative Strategies in International Business, D.C. Heath and Company, Lexington, MA.

Doz, Y.L. and Hamel G. (1998) Alliance Advantage, The art of creating value through partnering. Harvard Business School Press.

Duysters, G.M., Kok, G. and Vaandrager, M. (1999) Crafting strategic technology partnerships, $R \& D$ Management, 29, 343-351.

Gulati, R. (1998). Alliances and networks. Strategic Management Journal, 19, 293 317.

Hagedoorn, J. (1990) Organizational modes of inter-firm cooperation and technology transfer. Technovation 10, 17-30.

Hamel, G., Doz, Y. and Prahalad, C. (1989) Collaborate with your competitors and win, Harvard Business Review, 67, 1, 133-139.

Harbison, J.R. and Pekar, P. jr. (1998) Smart Alliances, A practical guide to repeatable success, BoozAllen \& Hamilton, Jossey-Bass Publishers, San Francisco. 
Harbison, J.R., Pekar, P.jr., Viscio, A. and Moloney, D. (2000) The Allianced Enterprise: Breakout Strategy for the New Millennium, BoozAllen \& Hamilton.

Hill, R.C. and Hellriegel, D. (1994) Critical contingencies in joint venture management: some lessons for managers, Organization Science, 5, 594-607.

Ireland, R.D., Hitt, M.A. and Vaidyanath, D. (2002) Alliance management as a source of competitive advantage, Journal of Management, 28, 3, 413-446.

Johnson, J.L., Cullen, J.B., Sakano, T. and Takenouchi, H. (1996) Setting the stage for trust and strategic integration in Japanese-U.S. cooperative alliances, Journal of International Business Studies, 27, 981-1004.

Kale, P., Dyer, J.H. and Singh, H. (2002) Alliance capability, stock market response, and long term alliance success: the role of the alliance function, Strategic Management Journal, 23, 8, 747-767.

Kale, P. and Singh, H. (1999) Alliance capability and success: a knowledge-based approach, working paper, Wharton School, University of Pennsylvania.

Khanna, T., Gulati, R. and Nohria, N. (1998) The dynamics of learning alliances: competition, cooperation, and relative scope, Strategic Management Journal, 19, 193210.

Lane, P.J. and Lubatkin, M. (1998) Relative absorptive capacity and interorganizational learning, Strategic Management Journal, 19, 5, 461-477.

Lorange, P. and Roos, J. (1990) Strategic Alliances, Formation, Implementation and Evolution, Cambridge, MA: Blackwell.

Madhok, A. and Tallman, S.B. (1998) Resources, transactions and rents: managing value through interfirm collaborative relationships, Organization Science, 9, 3, 326339. 
Margulis, M. and Pekar, P. (2001) The Next Wave of Alliance Formations: Forging Successful Partnerships with Emerging and Middle-Market Companies, Houlhan Lokey Howard \& Zukin.

Nault, B.R. and Tyagi, R.K. (2001) Implementable mechanisms to coordinate horizontal alliances, Management Science, 47, 6, 787-799.

Park, S.O. and Ungson, G.R. (2001) Interfirm rivalry and managerial complexity: a conceptual framework of alliance failure, Organization Science, 12, 1, 37-53.

Pisano, G.P., Bohmer, R.M.J. and Edmondson, A.C. (2001) Organizational differences in rates of learning: evidence from the adoption of minimally invasive cardiac surgery, Management Science, 47, 6, 752-768.

Poppo, L. and Zenger, T. (2002) Do formal contracts and relational governance function as substitutes or complements?. Strategic Management Journal, 23, 8, 707725.

Porter, M.E. and Fuller, M.B. (1986) Coalitions and global strategies. In Porter, M.E. (ed.) Competition in Global Industries, Boston MA: Harvard Business School Press.

Rugman, A.M. and Verbeke, A. (2002) Edith Penrose's contribution to the resourcebased view of strategic management, Strategic Management Journal, 23, 8, 769-780.

Simonin, B.L. (1997) The importance of collaborative know-how: an empirical test of the learning organization, Academy of Management Journal, 40, 5, 1150-1174.

Spekman, R.E., Isabella, L.A. and MacAvoy, T.C. (1999) Alliance Competence, Maximizing the value of your partnerships, John Wiley \& Sons, New York.

Steiner, G.A. (1968) Strategic Factors in Business Success, Los Angeles: University of California Graduate School of Business Administration. 
Vanhaverbeke, W., Duysters, G and Noorderhaven N. (2002) External Technology Sourcing through alliances or acquisitions: An analysis of the Application Specific Integrated Circuits Industry, Organization Science, 13, 714-733 


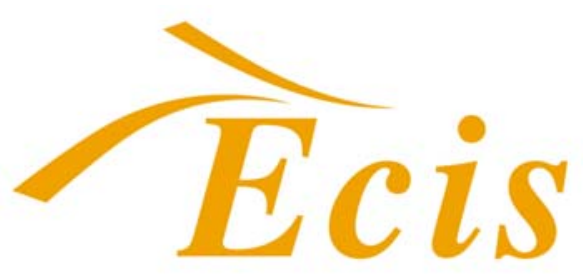

Eindhoven Centre for Innovation Studies

\section{W O R K I N G PA P E R S}

Ecis working papers 2002-2003 (July 2003):

02.01 M. van Dijk

The Determinants of Export Performance in Developing countries: The Case of Indonesian manufacturing

02.02 M. Caniëls \& H. Romijn

Firm-level knowledge accumulation and regional dynamics

02.03 F. van Echtelt \& F. Wynstra

Managing Supplier Integration into Product Development: A Literature Review and Conceptual Model

02.04 H. Romijn \& J. Brenters

A sub-sector approach to cost-benefit analysis: Small-scale sisal processing in Tanzania

$02.05 \quad$ K. Heimeriks

Alliance Capability, Collaboration Quality, and Alliance Performance: An Integrated Framework.

02.06 G. Duysters, J. Hagedoorn \& C. Lemmens

The Effect of Alliance Block Membership on Innovative Performance

02.07 G. Duysters \& C. Lemmens

Cohesive subgroup formation: Enabling and constraining effects of social capital in strategic technology alliance networks

02.08 G. Duysters \& K. Heimeriks

The influence of alliance capabilities on alliance performance: an empirical investigation.

02.09 J. Ulijn, D. Vogel \& T. Bemelmans

ICT Study implications for human interaction and culture: Intro to a special issue

02.10 A. van Luxemburg, J. Ulijn \& N. Amare

The Contribution of Electronic Communication Media to the Design Process: Communicative and Cultural Implications

02.11 B. Verspagen \& W. Schoenmakers

The Spatial Dimension of Patenting by Multinational Firms in Europe

02.12 G. Silverberg \& B. Verspagen

A Percolation Model of Innovation in Complex Technology Spaces 
02.13 B. Verspagen

Structural Change and Technology. A Long View

02.14 A. Cappelen, F. Castellacci, J. Fagerberg and B. Verspagen

The Impact of Regional Support on Growth and Convergence in the European Union

$02.15 \quad$ K. Frenken \& A. Nuvolari

Entropy Statistics as a Framework to Analyse Technological Evolution

02.16 J. Ulijn \& A. Fayolle

Towards cooperation between European start ups: The position of the French, Dutch, and German entrepreneurial and innovative engineer

02.17 B. Sadowski \& C. van Beers

The Innovation Performance of Foreign Affiliates: Evidence from Dutch Manufacturing Firms

$02.18 \quad$ J. Ulijn, A. Lincke \& F. Wynstra

The effect of Dutch and German cultures on negotiation strategy comparing operations and innovation management in the supply chain

02.19 A. Lim

Standards Setting Processes in ICT: The Negotiations Approach

02.20 Paola Criscuolo, Rajneesh Narula \& Bart Verspagen

The relative importance of home and host innovation systems in the internationalisation of MNE R\&D: a patent citation analysis

02.21 Francis K. Yamfwa, Adam Szirmai and Chibwe Lwamba

Zambian Manufacturing Performance in Comparative Perspective

03.01 A. Nuvolari

Open source software development: some historical perspectives

03.02 M. van Dijk

Industry Evolution in Developing Countries: the Indonesian Pulp and Paper Industry

03.03 A.S. Lim

Inter-firm Alliances during Pre-standardization in ICT

03.04 M.C.J. Caniëls \& H.A. Romijn

What drives innovativeness in industrial clusters?Transcending the debate

03.05 J. Ulijn, G. Duysters, R. Schaetzlein \& S. Remer

Culture and its perception in strategic alliances, does it affect the performance? An exploratory study into Dutch-German ventures

03.06 G. Silverberg \& B. Verspagen

Brewing the future: stylized facts about innovation and their confrontation with a percolation model

03.07 M.C. Caniëls, H.A. Romijn \& M. de Ruijter-De Wildt

Can Business Development Services practitioners learn from theories on innovation and services marketing?

03.08 J.E. van Aken

On the design of design processes in architecture and engineering: technological rules and the principle of minimal specification 
03.09 J.P. Vos

Observing Suppliers observing Early Supplier Involvement: An Empirical Research based upon the Social Systems Theory of Niklas Luhmann

$03.10 \quad$ J.P. Vos

Making Sense of Strategy: A Social Systems Perspective

03.11 J.A. Keizer \& J.P. Vos

Diagnosing risks in new product development

03.12 J.M. Ulijn, A. Fayolle \& A. Groen

European educational diversity in technology entrepreneurship: A dialogue about a culture or a knowledge management class?

03.13 J.M. Ulijn, S.A. Robertson, M. O'Duill

Teaching business plan negotiation: How to foster entrepreneurship with engineering students

03.14 J.E. van Aken

The Field-tested and Grounded Technological Rule as Product of Mode 2 Management Research

$03.15 \quad$ K. Frenken \& A. Nuvolari

The Early Development of the Steam Engine: An Evolutionary Interpretation using Complexity Theory

03.16 W. Vanhaverbeke, H. Berends, R. Kirschbaum \& W. de Brabander

Knowledge management challenges in corporate venturing and technological capability building through radical innovations

03.17 W. Vanhaverbeke \& R. Kirschbaum

Building new competencies for new business creation based on breakthrough technological innovations

03.18 K.H. Heimeriks \& G.M. Duysters

Alliance capability as mediator between experience and alliance performance: an empirical investigation into the alliance capability development process

03.19 G.M. Duysters \& K.H. Heimeriks

Developing Alliance Capabilities in a New Era 